\title{
Embodied Airborne Imagery: Low-Altitude Urban Filmic Topography
}

\author{
Amir Soltani \\ University of Cambridge \\ Department of Architecture \\ Cambridge CB2 1PX, UK \\ amir@metrowave.co.uk, as2135@cam.ac.uk
}

\begin{abstract}
Aerial photography has been the leading method for collecting and mapping information via remote sensing from the environments such as cities. Usually the qualitative analysis of the images is performed by human observation in a form of descriptive pattern recognition and manual spatial associations. These techniques for many years have created unique means of remote sensing whether through software analysis of photographic or satellite data, however, they have always been recorded from high-altitudes using predominantly airplane, helicopter or satellite information where the resulting graphical product such as Google map is disembodied and detached from the real visible qualities which are evident in human scale. These maps reduce the city spaces into densities and statistics (Penz 2010). The purpose of this study is to reuse this already established technology in a way to reintroduction visualisation techniques that can be useful in the perception of the city and its architectural spaces. Using cinematic mode of representation, particularly the use of moving image and still image to recognize their aesthetics, the density and other qualitative information from specifically a low level altitude where the images can be embodied revealing their sensory such as haptic and other modality qualities.
\end{abstract}

Aerial Photography. Cinematic Aided Design. Embodiment. Filmic Topography.

\section{INTRODUCTION}

For centuries aerial imagery and mapping have been utilised through drawings, paintings, and photography; we've seen maps decorated with descriptive human body elements describing places and locations with actions, these early maps were embodied version of what today's maps similarly are explaining to us. This is contradicting to the Google aerial maps where the human body associations are not clear and one wouldn't really be able to recognise the details of the lived space and the intensity of its places. The purpose of using low-altitude urban filmic mapping is to create a method which considers the view of the city from a higher vantage point using aerial photography and aerial perspective as an informative way of dealing with the city's personal topography in relation to the ground view. In filmmaking the perceptual understanding of cinematic aerial experience is created using methods of creative geography and topographical coherency (Penz 2010) through montage and different spatial narrative techniques which give symbolic and embodied significance in the form of cinematic mapping. Furthermore, we have had centuries of painters depicting the cities through combinations of mapping of both linear and aerial perspectival views; this sort of bird's-eye view spectatorship of the city reveals new imaginative aspects of urban space. Paper's hypothesis argues perhaps it is truly in cinema that we've been able to negotiate this sorts of top down views of city's topographic information and creating bird's-eye views that are both graphic and haptic exposing lived experiences of locations.

\subsection{Historical Context: Bird's-Eye vs. Embodied}

Aerial photography has been a fascination of planners that had the desire of envisioning a utopian projective image of the earth for their planning of the city (Vidler 2000).The first successful aerial photography was taken by Gaspard Felix Tournachon known as Nadar around 1856-58 and since then thousands of different images of the earth have been taken from different distances, as far as the moon. The aerial image of the earth and the city is a cross between the real and surreal through privileged instruments (ibid). Similar to the early maps where people, narrative and actions where built-in, cinematic mapping uses various ways of negotiating the mobile views through camera motion by overlapping, zooming, panning, tracking and traversing the shots and other montage methods to give the perception of an embodied city topography. This paper explains 
research experiments at the University of Cambridge Digital Studios (DIGIS) in the Architecture Department as part of exploring the images of the city from the point of views where we can combine the aerial perspective with the ground-human point of view and possibly understand some of the parameters that can be studied through this combination. As the American city planner Kevin Lynch said one of the most interesting parts of a map is what is not there, the people. Using filmic topography we can add them back particularly by means of low-altitude aerial imagery we can correlate the spatial boundaries of the city with its corporeal representation simultaneously.

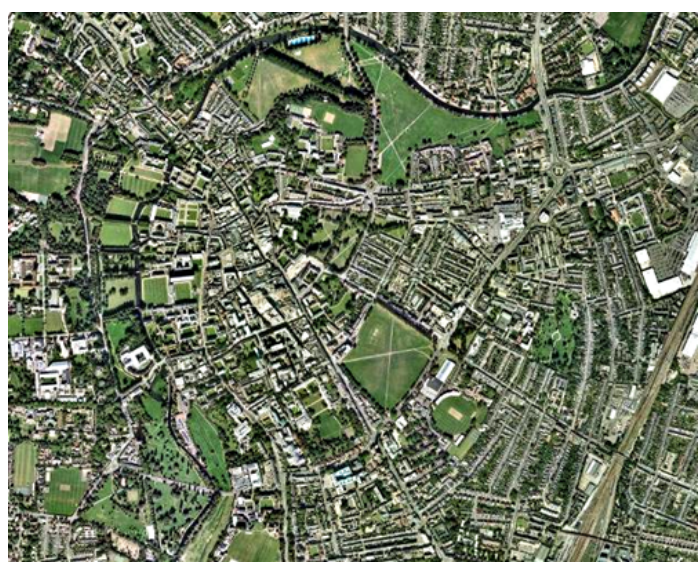

Figure 1: Google map of Cambridge

\subsection{Urban and Aerial Mapping Context}

In the $17^{\text {th }}$ century Queen Elizabeth granted John Speed permission to utilise a room in the Custom House where he was encouraged by William Camden to begin his Historie of Great Britaine ${ }^{1}$, which was published in 1611. Speed besides working on historical accounts did some important map-making, his town plans which are considered significant contribution and many of them provide the first visual record of the British towns. They are a combination of aerial perspectives and maps with descriptive drawings, notes, and symbols.

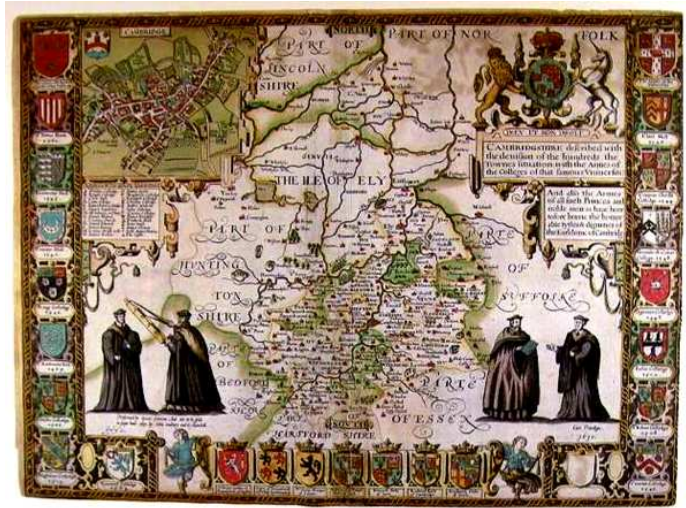

Figure 2: Early map of Cambridge by John Speed c. 1610

Michel De Certeau called aerial views as 'totalization' (De Certeau 1988: 11) meaning the modern aerial imagery are more accurate but less embodied version of old maps; these modern maps are separated from humans who instead embody the space through observer's walking motion traversing through diverse places. The cinema's narrative qualities however through storytelling has managed to add the human body and emotion back into these aerial views, analogous to the impressions from old maps they have been able to explain an urban topography as a haptic embodied experience. Therefore, rather than having a usual bird's-eye view which reduces the city into densities and statistics like the Google maps, filmic topography will embody the human emotional representation and becomes expressive and more experiential.
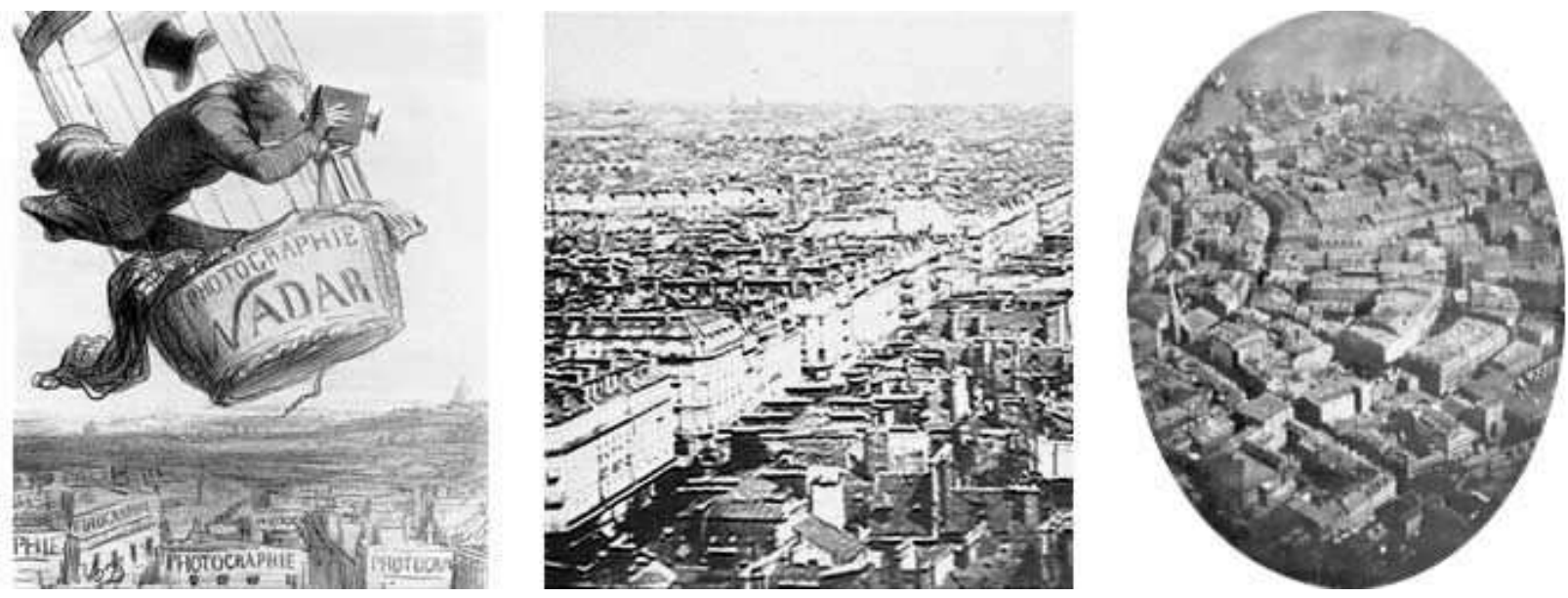

Figure 3: Nadar aerial photography c.1856 
Rolland Barthes commented that panoramic aerial vision recognises nothing other than a nicely connected space (Leach 1997:176). On the contrary, Guiliana Bruno describes the creative impossible viewpoint" (Bruno 2002: 177). Da Vinci's early attempts was "to turn earthbound observation into aerial vision in his oblique map of Milan" (ibid). Bruno quotes Louis Martin who suggested that artist-cartographer travelling places is depicting bird's-eye views that "gives us a snapshot of the city" (ibid). Bruno considers this as an encounter between map and the landscape disagreeing with the totalising perspective that often is associated with a "superior eye," rather considering aerial views from imagined "nowhere and now here;" she continues that this imaginative "dislocated view, made possible much later by the spatiovisual techniques of cinema, attempted to free vision from a singular, fixed viewpoint, imaginatively mobilising visual space (ibid).

\section{PROJECT'S SPECIFICATION}

The low-altitude aerial mapping project is an experiment in-progress attempting to examine the possibilities of incorporating alternative methods of visualisation by revealing urban topographies that can include embodied features like sensory, and gestural analysis amongst others. The following is a brief description of its prototype, and methodology. The final results and evaluations will be at the end of summer 2011.

\subsection{The Methods: KAP vs. Helium Balloon}

Low-altitude filming and photography have become more popular since the digital cameras become more accessible to the public and no longer is an specialised field; however, its uses have not been addressed in many environmental and scientific research domains until the last few decades. The first known attempt to take aerial photographs was by Colonel Aimé Laussedat of the French Army Corps of Engineers (Wolf and Dewitt 2000) ${ }^{2}$. He tried both balloon and kite but wasn't successful until Nadar in 1858 managed to photograph villages of Petit Bicetre in Clamart near Paris. In early $20^{\text {th }}$ century the kite was the most widely method of lifting cameras up to the sky which replaced the balloon that was prominent instrument of aerial photography from the mid $19^{\text {th }}$ century. Since balloon method was too costly and dangerous and the use of airplane were beginning but also risky, kite aerial photography (KAP) become the most favoured means and was used as "utilitarian method for scientific surveys, military applications, and general viewing of the Earth's surface." ${ }^{3}$ Following the WWII there was a renewed interest in kite photography in the United States and eventually in 1985 "the Kite Aerial Photography Worldwide Association (KAPWA) was founded". As elements of early artist-cartographer as Leonardo da Vinci's depicting a bird's-eyes view as "an imaginary perspective, taken from an

the interests in kite photography increased a quarterly journal called Aerial Eye ${ }^{4}$ was produced in 1994-99. Currently the advancement of technology in kite flying is contributing to its popularity growth and aerial photographic applications in the future.

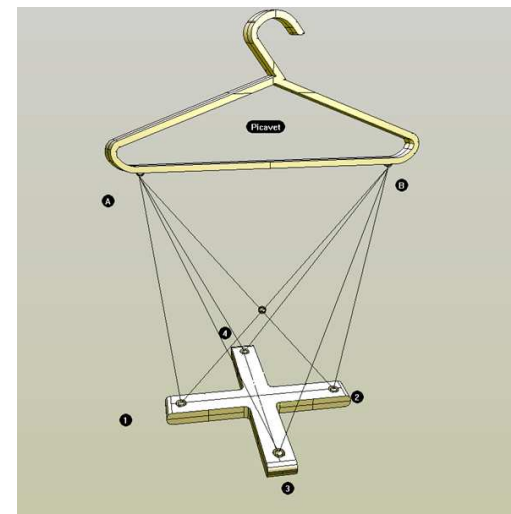

Figure 4: Picavet suspension dampened system to keep the camera level to the ground plane

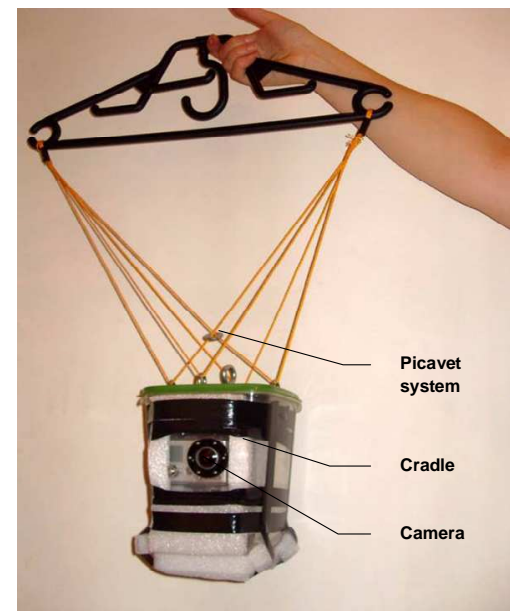

Figure 5: The Picavet rig and camera cradle

However, for the purpose of this project which demanded steady and slow survey of architecture and the city streets kite wasn't the best choice, rather a balloon aerostat served as an improved vehicle for aerial low-altitude filming. This was due to the fact that unlike kite that needs the force of wind for navigation, a hand controlled balloons through one or two tethered lines worked nicely in a calm day and allowed the attached camera cradle to get close to the buildings; in addition the balloon rig utilised a suspension dampening system for the camera first designed by Pierre Picavet, France (1912), which allowed it to stay level to the ground plane at all times despite any movement caused by wind. Helium is used to lift the 5-7 foot diameter meteorological balloon, its camera and the Picavet rig to the sky. 


\subsection{Aerial Perspective and Visual Cues}

In aerial view is one type of perspective there has various parameters that are affected by vision; for instance, the light, the contrast and the vividness of the colours are changed according to the distance. When traditional aerial maps and photography are enhanced they get rid of some of the visual nuances that are actually representations of the distance. We know that when objects are far away, there is a spatial distance between the eyes and the object, the light is more scattered and there is a reduction in contrast, less vividness of the colour and objects may seem to be blurred. This information gives us the relevant distance and proximity of the objects that are viewed in a scene; therefore, "contrast is a function of the distance from the object to the viewer and of the degree of clarity of the atmosphere" (Hershenson 1997: 96).

O'Shea et al. (1994) have written that it is not necessary to have objects such as dust and particles blocking the view, given in a perfectly clear day distance create these kinds of phenomena such as lower contrast. Hence, aerial perspective gives us many visual cues to the depth of our scene. We see this also in paintings and drawings that depict atmospheric creation of aerial perspective adding depth in a $2 \mathrm{D}$ picture; in experiments that O'Shea et al. (1994) did he put various samples of the different contrast scenes to see whether changing the contrast or altering the tonal variations result in simulation of distance. $\mathrm{He}$ concludes that "contrast is a pictorial cue to depth that acts by simulating aerial perspective" (ibid: 97) and the scenes with a higher contrast simulated objects to be closer than the ones with the lower contrast.

Merleau Ponty mentions pictorial cues of Cezanne's paintings in the sense of livedexperience which is the opposite of the classical doctrine of perspective that depicts landscapes according to certain symbolic perspective through a singular gaze. These landscape depictions of space are really detached from the way that human body experiences a real landscape. As in the old landscape paintings, the viewer generally feels a sort of suspended viewpoint from where s/he is attached as if the landscape passes through them and its qualities remain at distance not involving the viewer. Merleau Ponty calls it 'held beneath a gaze which is fixed at affinity,' the point of perspective on the painting is not the same in real world landscape, as we confront many obstacles that we have to look through to create a singular landscape viewpoint, perhaps through trees and other objects that overlap each other; thus, through many different snapshots of their positions in the landscape we create in mind the perception of the whole picture. It is not non-resistant as the classical paintings which portray the landscape; we are challenged by different visual impressions that are really difficult to draw in one painting.

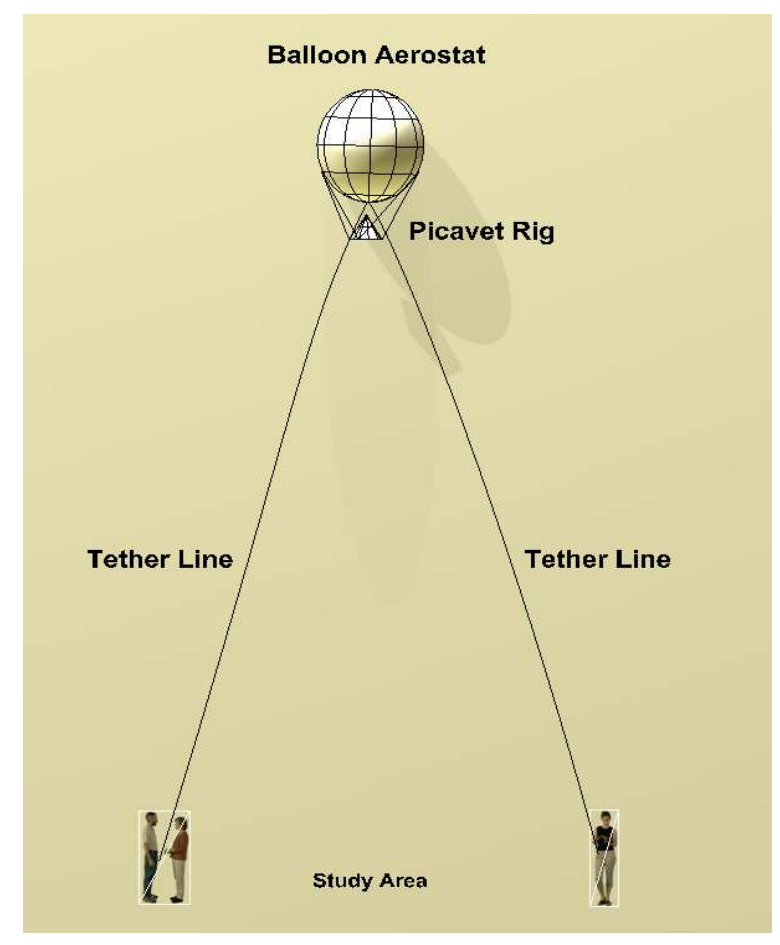

Figure 6: Two tethered line control

Similarly in the low-altitude filmic mapping project we wanted to get as close to these obstacles as possible; the objects that remained in our viewpoints when we look at a cityscape on a day to day basis. Only then we can understand some of the cues and nuance perceptual visual phenomena such as parallax vision, proximity, and view depths.

\subsection{Split-Screen, Projection Mapping, and Multi-Layered Data Narrative Methods}

Computer modelling and ultimately digital projection mapping of the aerial views generate different kinds of information regarding the representations of a city and its architecture. One of the project's aims is to fit different types of information in a single viewport that convey a singular visualisation, similar to the computer generated model of an architecture that different application of its texture, colour, viewpoints are determined by the architect. In order to have a more steady movement through the streets two tethered line is utilised and the resulting footage is shared between three different methods used in the visualisation of the aerial mapping:

(i). Split-screen data/viewpoint montage.

(ii). Multi-viewpoint projection mapping.

(iii). Sequential framing mosaic. 


\section{CASE STUDY}

The project started in early 2011 and Cambridge Streets was chosen as the subject of the initial case study in low-altitude aerial mapping. The highly diverse styles of architecture and picturesque historical viewpoints become part of the testing ground in questioning how the filmic mapping of the city from above will contribute knowledge and understanding of its spatial and formal structure?

\subsection{Flight Lines and Altitudes}

Original aerial photography has been taken using various types of platforms such as airplane, helicopter, balloon, kites, and even tall buildings; the airplane remains the most common which uses tiling and overlapping of images in patterned flight paths to achieve large aerial mapping. The flight path of a whole area is done by "usually $60 \%$ overlap along each flight line and a $20 \%$ overlap between flight lines." By using small weather balloons for creating ideal conditions like slow moving camera, close proximity to tall places, lowaltitude bird's-eye views of the city, and controlled navigation through specific streets and areas that is impossible to use airplane, helicopter, or any other platforms.

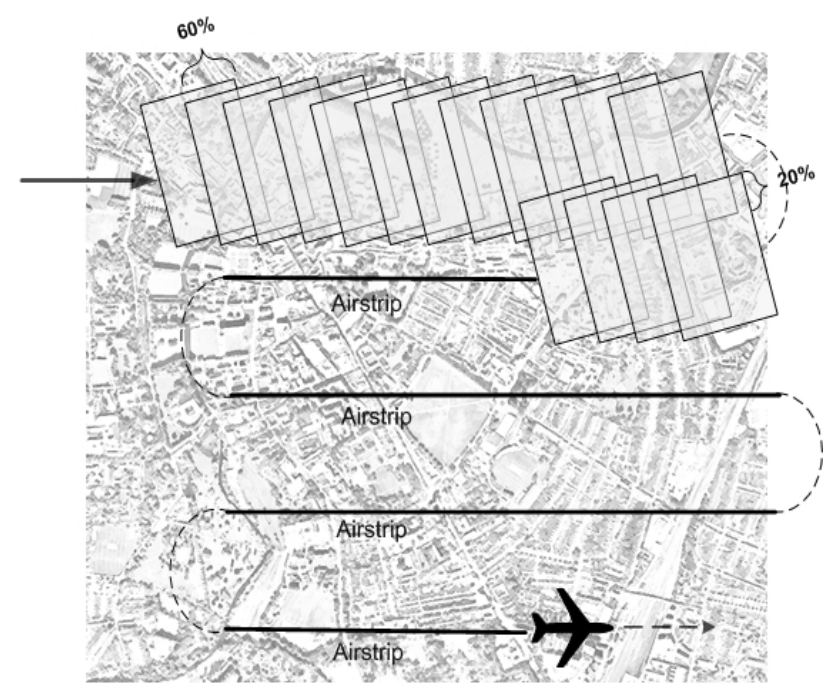

Figure 7: Traditional aerial mapping flight path and pattern of visualisation layouts

Three different types of visualising aerial maps is compared with the ground footage creating a new spatial representation of cinematic cartography using oblique, vertical, and ground points of views. Furthermore, the 3D stereoscopic oblique shots is utilised to explore the 3D space of the buildings from close-up, similar to the way we perceive 3D depth through binocular vision. In ideal settings it is possible to derive variety of useful qualitative and quantitative information regarding the behaviour of built environment including surveying the size, shape, texture, patterns and gesture among other.

These data will be associated with space including its usage by people as it an embodied technique to urban mapping analysis. The degrees of complexity differs from the traditional aerial photography as the primary element will be tone and colour to the secondary degree of complexity which are size, shape, and texture up to usage of the site and its associations. Using this methodology we can add new spatial arrangements to the aerial mapping strategies that already existed and use it in conjunction. Here the cameras become sensors that through detail observation and the descriptive cinematic aided design methodology we can decipher a range of meanings from digital images that are combined and visualised as a whole.

\subsection{Vertical vs. Oblique: Flat vs. Perspectival}

The traditional aerial photography is either vertical or oblique and usually the photographs are slightly overlapped or tiled to create coverage of the whole area, these are usually the vertical photograph which is less than 3 degrees from the tilt degree from the ground. In the oblique we have angle of 3 to 90 degree from the Nadir direction and it creates an oblique aerial photograph of the area. Another method is stereoscopic that takes two photographs simultaneously to create 3D depth imagery and is viewed using a stereo image similar to the stereogram. In this experiment we try to combine the traditional analysis of vertical and oblique aerial photography with a low-altitude airborne system where we can get close to the built environment and combine three different type of visualisation: first a flat filmic mapping based on the vertical view, then an oblique perspective view of the city which can also be achieved through stereo imagery creating a 3D perspective, and finally ground view shots are taken concurrently. These combined views would be synchronised to create one-to-one correlation giving different types of information rather than just statistics or density, instead spatial and sensual information is possible through filmic split-screen and cinematic mapping methods of controlling moving spatiotemporal information. Therefore, we are not interested only in the earth or a city surface, but rather in its spatial and sensory qualities benefiting from aerial and ground data.

\subsection{Visualisation Layouts}

The oblique aerial films were recorded at $30-60$ frames per second as well as the vertical was timelapse photographed every $5-10$ seconds giving various temporal impressions of the city. In the next phase of the project analysis these footage where divided into the three methods of visualisations and they once more captured as a single presentation. 


\subsubsection{Split-screen Data/Viewpoint Montage}

In an attempt to incorporate data, information and quantitative measurements simultaneously, the split-screen method commonly used in the cinema was utilised in it multiple shots. Data is assembled side by side within a single frame creating the idea of simultaneous action. In 1950's and 1960's cinema split-screen was often used to depict phone conversations as well as being used in classic horror films. Today in Hollywood cinema splitscreen is not limited to genre and it has been revived in many ways. Van Sijll describes splitscreen as a way to exploit "the elasticity of time and place...to heighten the suspense of the scene" (Van Sijll 2005: 58).

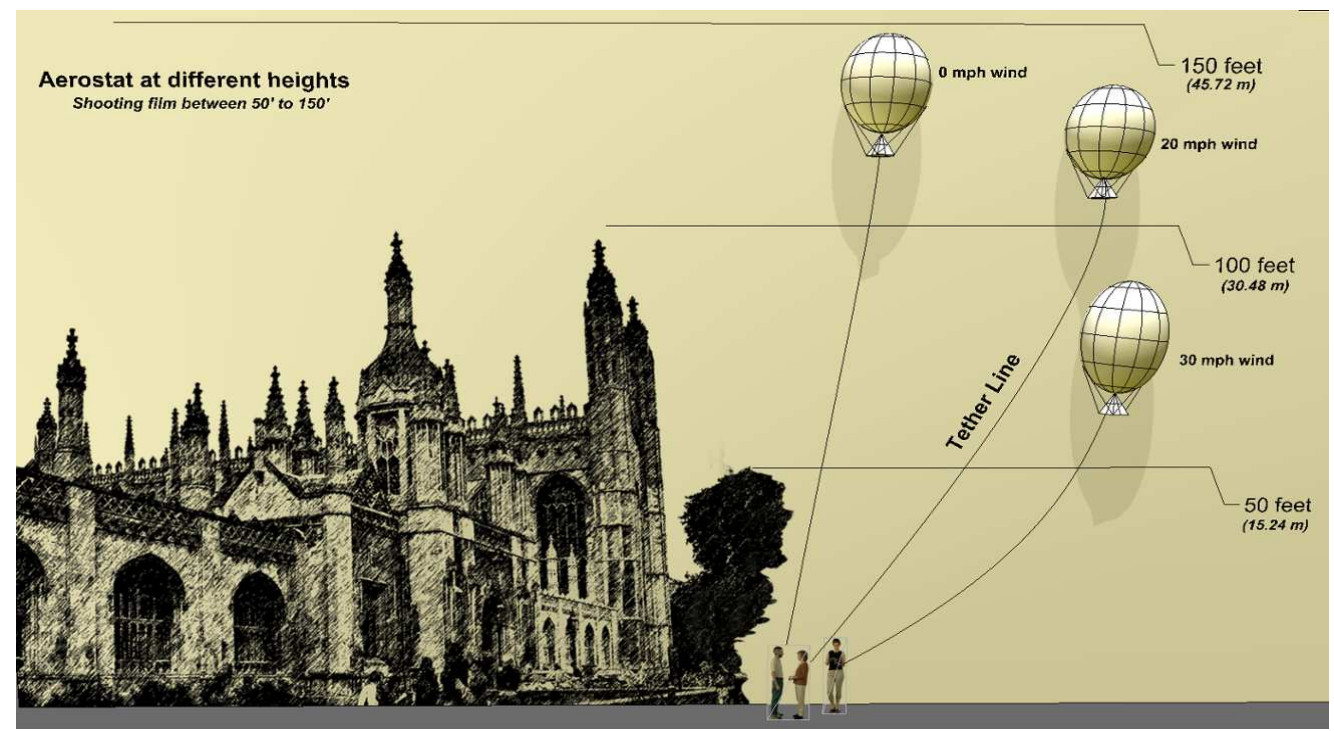

Figure 8: Kings College Cambridge was one of the targets for the low-altitude aerial filmic mapping

\subsubsection{Multi-viewpoint Projection Mapping}

Similar to split-screen projection mapping explores the idea of simultaneous events using multiple views however the results can be used in an installation in physical space where observer's body can interact with the results. Projection mapping on facades has been popular in the last few years with the help of advancement in the computer programming and the accessibility of the projectors as the prices of electronics fallen enabling visual artists to explore the spatial domains of projecting on to architectural surfaces and altering it in a non-permanent ephemeral rendition. Using three projectors positioned in different angles each depicting one of the views using graphical programming software, the city plans are visualised in 3D space where it can be embodied by viewers.

\subsubsection{Sequential Framing Mosaic}

This third method was mainly to examine temporal framing of the aerial footage individually. The landscape and architecture similar to people can have gestures depicting the trajectory of some motion. Through sequential framing the gesture of the land, patterns and topographic qualities of the city streets and behaviour of the people occupying them are revealed. The results create a haptic framing of gestural motion and visual structure of the dynamics from the aerial mapping.
There are other methods to combine the three views acquired in this project which can reveal yet new possibilities of visualising topographic information from built environment; however, all of these methods share the cinematic aided design strategies for mobilising and simulating time space of our lived experience in a multidimensional approach.

\section{EVALUATIONS}

\subsection{Sense of Visual Empowerment and the Embodied Space}

Using paintings as explanations Merleau Ponty defines how we embody the space and objects that exist according to our personified subjects, and our body experiences in relationship to space. For instance, Merleau Ponty mentions an interesting example of how the moon seems different sizes, when it is seen at the horizon which appears larger than when it is seen from the sky above us (Merleau Ponty 1948). He means when we look at the moon in the horizon we may compare it to many other objects which we have to first look through like trees, houses, hills, mountains; we compare the size of the moon to these objects and therefore we judge its size as perceived larger at horizon than when it is in a vast empty sky not 
compared with other objects hence appearing smaller, this is a psychological illusion (ibid). This example of how we embody the different experiential properties while we experience the moon depends to our perceptual fields. Similarly the psychological geometry of a room changes its shape as a result its space having different regions, when we privilege or prefer some action according to our senses triggered through our bodies at different situations. Therefore, the emphasis of mind 'and' body aren't separate as it sounds rather mind is 'with' the body a more correct way of thinking and gaining access to our bodies and objects through the qualities that we combine using our senses.

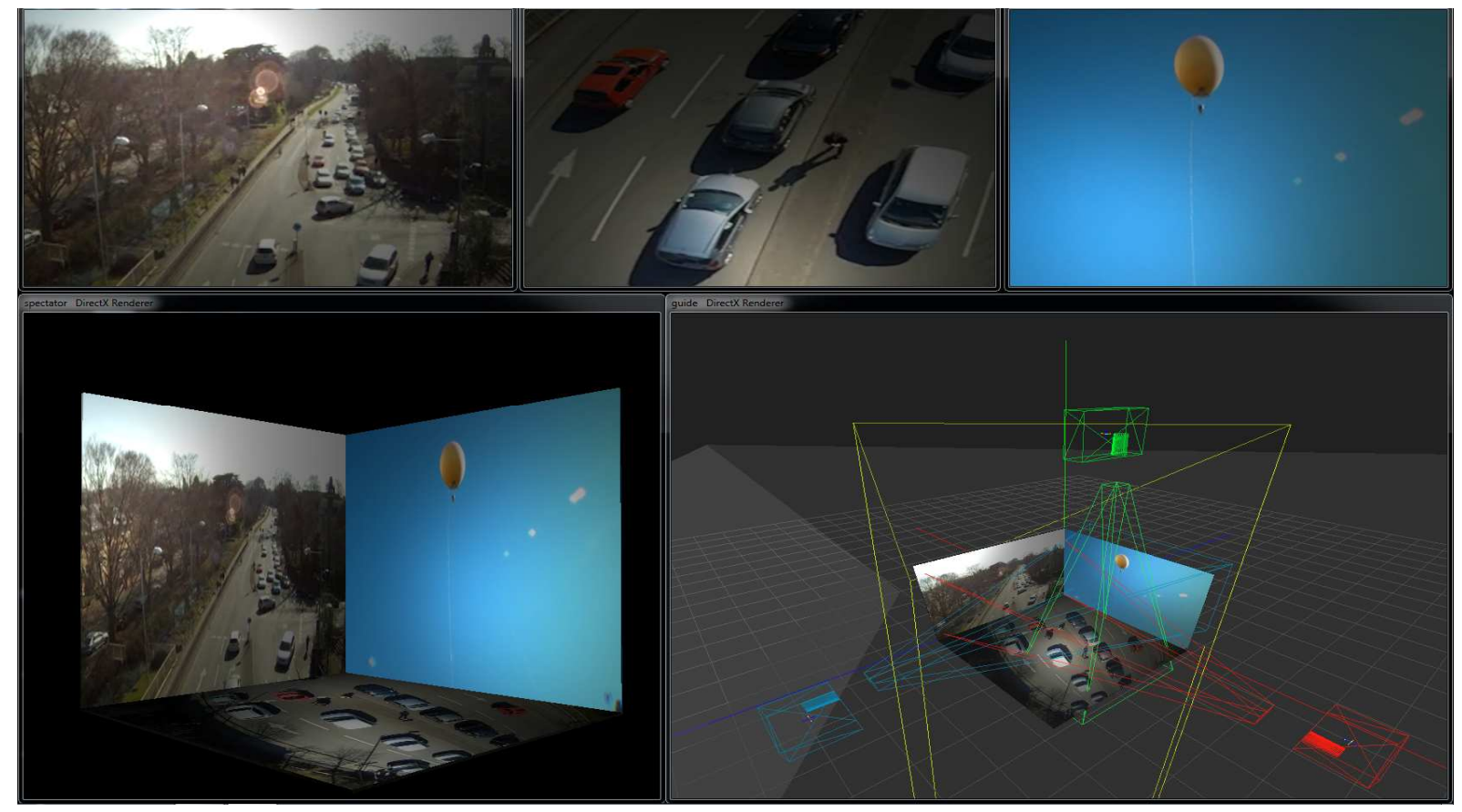

Figure 9: Projection mapping interface of 3 simultaneous views

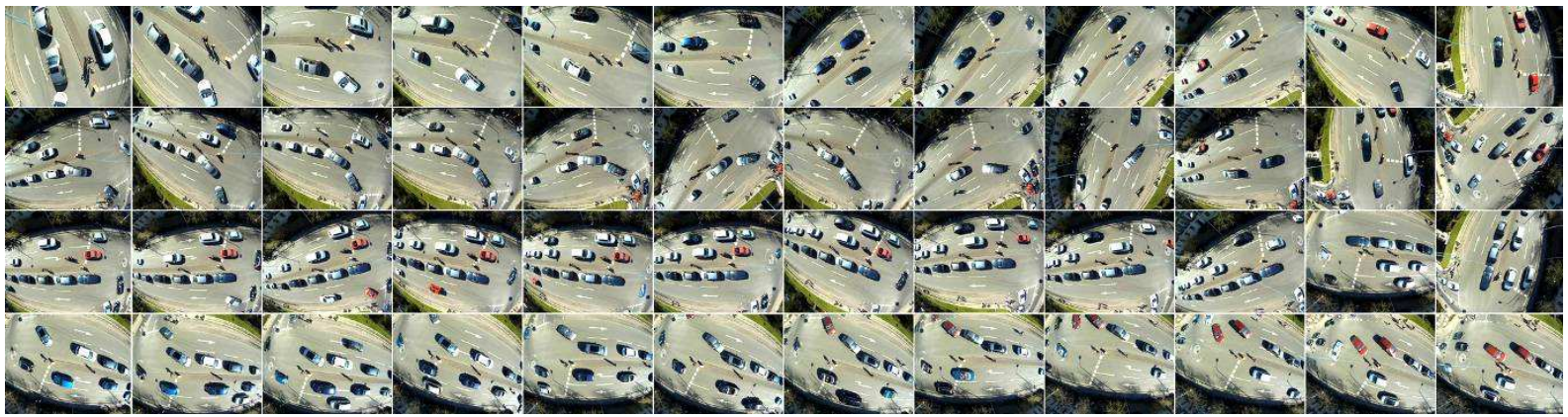

Figure 10: Sequential framing mosaic: a frame every 5 seconds

Merleau Ponty says everything I see is in principle within my reach, at least within reach of my sight, marked on the map of the 'I can' (Virilio 1994:7). Virilio points that here Merleau Ponty is really referring to something that eventually through 'teletopology' will be ruined by the mundane and 'banalisation' that it's going to bring to life because major amount of what we see now is no longer within the reach of 'I can' and it is not marked on any map that is within reach of my sight; rather, everything that are televised and visualised really require a perception that in fact is against the previous (classic) mode of representation which was in an era without technology and where you could say that what I see, I can touch, I can reach and therefore 'I can.' Thus, traditionally the physical proximity in-sight was the people's empowerment.

\subsection{Cinematic Aided Design vs. Experiential Vision Machine}

In today's typical aerial maps the idea of aerial perspective has been almost completely erased because the clarity of the map is the most important factor; we see pictorial cues replaced with more technological cues because the aerial maps are meant to be used as analytical methods in spatially understanding maps. We can conclude that these machined aerial maps are not really true 
and in many ways what we see is not actually the true representation of the physical reality.

As Bruno points out staged bird's-eyes scenes depicted by the early artists' hands created a "spatial observation that opened the door to narrative space" and made the city to become "part of the sequence of imaginative survey." Later aerial views of the city in cinema became reconstructed mobile maps of the city (Bruno 2002: 266) and at the same time a cinematic aid in understanding the design of the city. A contemporary artist exploring the aerial filmic mapping is Olivo Barbieri who uses tilt-shift lens in his filmic and photographic works to alter our perception of landscapes, cityscapes, and crowds so that they appear as toy models ${ }^{6}$.

Merleau Ponty's concept of experiential vision, sensing with the body, and the embodied visualisation are ultimately considered the way we perceive the reality. In contrast Virilio uses his vision machine analogy to explain the importance to understand the coexistence of artificial intelligence, as the vision machine and the digital experience of it relate to an artificial reality. They can affect everything from our expectations to our expertise as in the aerial maps. Understanding the fundamentals of how the electronic optics both reads and writes is about how this "mode of representation of statistical thought" are dominating and contributing to the modes of reasoning and perception (Virilio 1994: 76).

\section{CONCLUSION}

In Hollywood's cinema the aerial shots have been used to portray a bird's-eye view creating a graphic rendition of the scene "which easily lend themselves to symbolic use" (Van Sijll 2005: 192). These types of shots graphically depict the narrative in the particular moment by showing eye catching, enthralling aerial image. Cinema has managed to capture our emotions through different senses to produce unique meanings of our environment creating perceptual viewpoints. Different layers and changes of space and objects are defined through these body sensory perceptions according to our own lived experiences. Merleau Ponty's writings on embodied experience of space are significant sources in understanding the filmic space relative to our different senses.

The low-altitude aerial mapping experiment and its post-visualisation techniques of simultaneous viewpoints are parallel to the ways we perceive the space with our bodies and senses. We collect different views and information from the environment through our haptic visual modes and combine perspectival information such as scale, direction, proximity, trajectory and many more to create integral understanding of our world. The goal of this project is to achieve an embodied close-up observation of these aerial views through cinematic aided methods triggering new creative models for reconsidering our bodies' sensory perceptions in the visualisation process by today's scientist-visual-artists. This is a work-in-progress and at this time cannot draw a full conclusion as the results of the analysis and evaluations are expected in the second half of 2011.

Aerial mapping has a long and successful history yet the adaptation of architectural and urban spaces to the body interventions with the aerial views, e. g. through the multi-viewpoints filmic mapping is a new way of staging experiential performance of the space which captures the multiplicity of its characteristics. In the low-altitude aerial mapping embodied space is materialised space by the collective cinematic experience of the body and haptic visuality.

\section{REFERENCES}

Bruno, G. (2002) Atlas of Emotion: Journeys in Art Architecture and Film. London, NY: Verso.

Hershenson, M. (1999) Visual Space Perception: A Primer. USA: MIT Press.

Leach, N. (Ed.) (1997) Rethinking Architecture: A Reader in Cultural Theory. UK: Routledge.

Merleau Ponty, M. (1948, 2004) Merleau Ponty: The World of Perception, Routledge, UK.

Penz, F. (2010) Cités-Ciné, from Department of Architecture Lecture, University of Cambridge, UK.

Penz, F. (2010) The Real City in the Reel City: Towards a Methodology through the case of Amélie. From Koeck, R., Roberts L. (Ed.). (2010). The City and the Moving Image Urban Projections London: Palgrave Macmillan.

Van Sijll, J. (2005) Cinematic Storytelling: The 100 Most Powerful Film Conventions Every Filmmaker Must Know. USA: Michael Wiese Productions.

Vidler, A. (2000) Photourbanism: Planning the City from Above and from Below from Bridge, G., Watson, S., A companion to the City, Blackwell Publishing, Oxford, UK.

Virilio, P. (1994) The Vision Machine, BFI Publishing, London, UK.

\footnotetext{
${ }_{1}^{1}$ http://en.wikipedia.org/wiki/John_Speed

${ }_{2}^{2}$ www.geospectra.net/kite/history/history.htm

${ }^{3}$ www.geospectra.net/kite/history/history.htm

${ }^{4}$ www.arch.ced.berkeley.edu/kap/background/kapa e.html

${ }^{5}$ http://grass.osgeo.org/grass62/manuals/html62_us er/photo.init.html

${ }^{6}$ http://www.olivobarbieri.it/
} 